DOI: $10.17805 /$ zpu.2019.3.6

\title{
Социокультурные трансформации: модели практического регулирования
}

\author{
Ю. В. ПОПКОВ
}

ИНСТИТУТ ФИЛОСОФИИ И ПРАВА СИБИРСКОГО ОТДЕЛЕНИЯ РАН, Е. А. ТЮГАШЕВ

НОВОСИБИРСКИЙ НАЦИОНАЛЬНЫЙ ИССЛЕДОВАТЕЛЬСКИЙ ГОСУДАРСТВЕННЫЙ УНИВЕРСИТЕТ

В статье актуализируется проблема зависимости описания форм и содержания социокультурных трансформаций от интерпретации самого концепта "социокультурный». Отстаивается положение о вариативности практического опыта регулирования социокультурных трансформаций. На основе экспликации концептуально значимых идей основоположника теории социокультурной динамики П. А. Сорокина анализируются конкретные модели практического регулирования социокультурных трансформаций.

Социокультурными трансформациями, протекающими в масштабе исторических эпох, знаменитый социолог называл качественные преобразования различных типов культур и сопутствующие им социальные изменения. Согласно учению П. А. Сорокина, в зависимости от разных оснований можно выделить несколько типов социокультурных трансформаций: по формам социокультурной самоорганизации, по формам культурной интеграции, по формам логически интегрированных культур. Модели практического регулирования П. А. Сорокин описывал по отношению к долгосрочным социокультурным трансформациям логически интегрированных культур.

По результатам проведенного им анализа динамики чувственной культуры (на материале европейских обществ Нового времени) можно выделить следующие модели практического регулирования связанных с нею социокультурных трансформаций: модель сдерживания, договорно-принудительная модель, модель творческого и всеобщего лидерства. С учетом того, что современное российское общество также переживает переход от идеациональной к чувственной форме культуры, идейное наследие П. А. Сорокина может быть полезным для содержательной характеристики моделей практического регулирования актуальных социокультурных трансформаций.

Ключевые слова: социокультурная динамика; социокультурные трансформации; П. А. Сорокин 


\section{ВВЕАЕНИЕ}

【 деологически нейтральный концепт «социокультурная трансформация» активно

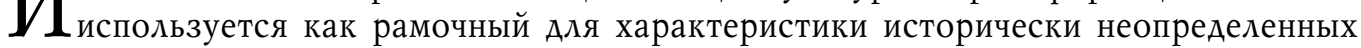
многовекторных преобразований в отдельных государствах и локальных сообществах (см.: Абрамова, Костюк, 2017). Так, например, пишут о трансформациях посттрадиционных, посткапиталистических, постсоциалистических, поставторитарных, посттоталитарных, постсоветских, посткоммунистических... Но наряду с идеологической нейтральностью данный концепт обладает парадигмальной относительностью, подразумевающей отнесенность к конкретной социокультурной парадигме, суть которой определяет описание форм и содержание выделяемых трансформаций.

Среди социокультурных парадигм наиболее известно учение П. А. Сорокина о социокультурной динамике (Сорокин, 2006а), которое до сих пор привлекает внимание исследователей (Mangone, 2018), не потеряв своей актуальности и эвристической значимости. Знаменитого социолога с полным основанием можно назвать приверженцем трансформационизма. Согласно его учению, в мире трансформации бесчисленны и разнообразны, совершаются через множество промежуточных конфигураций. В то же время социокультурные трансформации имеют ограниченный спектр форм реализации, циклически (и одновременно вариативно) повторяющихся. На основе выделения и содержательного описания этих форм возможно прогнозирование, а следовательно, и регулирование хода социокультурных трансформаций.

Задачей настоящей статьи является выявление представлений П. А. Сорокина о моделях практического регулирования социокультурных трансформаций с предварительным выделением типологии самих этих трансформаций. Основное внимание будет сосредоточено на моделях регулирования перехода общества к чувственной культуре как доминирующего для многих стран и народов.

\section{КАК РЕГУ ИИРУЮТСЯ СОЦИОКУ АЬТУРНЫЕ ПРОЦЕССЫ?}

Решая поставленную задачу, опишем, как П. А. Сорокин понимал регулирование социокультурных процессов. Известно, что последние воспринимаются им как имеющие две существенно значимые стороны: взаимообусловленное поведение индивидов и детерминация их социального взаимодействия со стороны культуры. Можно выделить несколько уровней регуляции человеческого поведения, как они представляются социологу.

Во-первых, это уровень животной регуляции, когда отдельный человек управляется инстинктами, вожделениями и страстями (Сорокин, 2014: 289). По образному сравнению П. А. Сорокина, в каждом организме имеется «динамо-машина», которая приводит его в движение и регулирует его поведение (Сорокин, 2015: 465).

Во-вторых, это уровень социальной (групповой) регуляции, например, когда индивиды (или группы) «становятся жертвами обмана и грубой силы» (Сорокин, 2014: 289). «Если же средств первой необходимости не хватает, неизбежно возникает регуляция», - пишет он применительно к данному уровню, касающемуся внешнего воздействия (Сорокин, 2006а: 647).

В-третьих, это уровень культурной регуляции, которая осуществляется через ценности: усвоенные человеком, они как бы изнутри управляют поведением людей (там же: 288).

Кроме того, с точки зрения П. А. Сорокина, объективно действует принцип имманентной саморегуляции социокультурных процессов. Аюбой процесс когда-то дости- 
гает «точки насыщения», после чего может идти в обратном направлении (там же: 104). Причиной этого является своего рода «износ» («истощение») процесса. Одновременно его протекание сопровождает сопротивление (противодействие) противоположной стороны взаимодействия, растущая активность которой уравновешивает исходный процесс и даже может менять его направление (там же: 111).

Таким образом, действующие механизмы регуляции социокультурных процессов, хотя и реализуются в поведении конкретных людей, существуют объективно. Поэтому модели практического регулирования социокультурных трансформаций должны быть не произвольно конструируемыми, они необходимо определяются конкретным содержанием последних.

\section{СОЦИААЬНЫЕ ТРАНСФОРМАЦИИ}

По мнению П. А. Сорокина, не существует единой, универсальной модели трансформации форм культуры и социокультурных систем (там же: 878-879). Исходя из его концепции, можно выделить несколько моделей социокультурных трансформаций, наблюдавшихся в истории.

Так, по его наблюдению, подтверждаемому данными экологии, в социальном организме в зависимости от ресурсных ограничений и сопутствующих им чрезвычайных событий (войн, катастроф, кризисов, революций) происходят постоянные маятниковые качания между полярными формами самоорганизации (и регулирования) общества - от тоталитарной формы к анархической (либеральной) форме. «В какой-то период сеть ее социальных взаимоотношений приближается к тоталитарному полюсу, и регулятивно-регламентарные функции ее правительства расширяются и усиливаются, - писал П. А. Сорокин о социальной группе (отметим, что он часто не различает ее с социальным организмом). - В другой — многие “фибры” сети отсеиваются, группа начинает приближаться к либеральному или анархическому типу, контроль и регулирование со стороны правительства уменьшается, а их экстенсивность сужается» (там же: 633-634).

Эти маятниковые качания П. А. Сорокин называет флуктуациями социальных отношений, происходящими между разными типами (режимами) саморегулирования в разные периоды существования социального организма («закон флуктуации тоталитаризма и свободы»). В каждый актуальный период времени (в синхронии) одни социальные организмы ближе к тоталитаризму, другие - к «либеральному» или «анархическому» типу.

Краткосрочные, частые и в известной мере случайные колебания форм социальной самоорганизации (а также сопутствующих им форм әкономики, управления, идеологии и образа жизни) напоминают П. А. Сорокину колебания ртути в термометре при изменениях температуры (Сорокин, 2014: 294). Он их называет тоталитарными и детоталитарными трансформациями, конверсиями и реконверсиями.

Эти трансформации охватывают не только общественную жизнь, но и культуру. По оценке П. А. Сорокина, в критических ситуациях организованная социальная группа приветствует тоталитаризм как положительную ценность (Сорокин, 2006а: 580). Ценностная определенность тоталитаризма позволяет идентифицировать его как социокультурную форму, входящую в пульсирующий цикл краткосрочных социокультурных трансформаций.

Полярными фазами данного цикла являются формы анархической и тоталитарной самоорганизации общества. Наряду с этим П. А. Сорокин упоминает либераль- 
ный (договорно-демократический) и авторитарный режимы самоорганизации, контроля и регулирования (там же: 578). Следовательно, они могут быть выделены как промежуточные формы модели социокультурной трансформации, протекающей по схеме: анархизм - либерализм - авторитаризм - тоталитаризм. Исключительно благоприятные условия позволяют вести анархический образ жизни. С усилением ресурсных ограничений и ростом экологической напряженности рыхлая социальная организация становится более жесткой, вплоть до тоталитарной, когда социальный организм действует как единое монолитное целое.

Это социокультурные трансформации, в которых главным детерминирующим фактором выступает социальная динамика, а тип культуры остается относительно неизменным. Выделенные социокультурные формы явно различаются степенью (уровнем) социальной интегрированности в пределах одной культуры. Поэтому представляется возможным ассоциировать их с описываемыми П. А. Сорокиным формами культурной интеграции.

\section{ТРАНСФОРМАЦИИ КУ БТУРНОЙ ИНТЕГРАЦИИ}

Напомним, что П.А. Сорокин различал четыре такие формы: конгломерация (скопление) - ассоциация под воздействием общего внешнего фактора - причинная (функциональная) интеграция - логико-смысловое целое. Если культурная конгломерация хаотична и беспорядочна, то логико-смысловое культурное целое - результат «сверхинтеграции»: «все части вместе образуют, так сказать, одежду, сшитую из одного куска ткани» (Сорокин, 2006а: 41). Поэтому можно сказать, что культурная конгломерация анархична, а логико-смысловая интеграция - тоталитарна (поскольку «сшита из одного куска ткани»).

Причинная (функциональная) интеграция конституирует тип системы, которую П. А. Сорокин сравнивает с автомобилем (или с организмом). Аетали такого целого соединены на основе общего каркаса (скелета), различных функциональных систем и при помощи особых внутренних «центров» управляются для достижения одной цели (там же: 37-38). Интеграция такого типа по режиму управления, очевидно, авторитарна. И она не допускает функционально неоправданного присоединения иных объектов, что возможно в свободной ассоциации.

П. А. Сорокин специально не описывал трансформации форм социальной самоорганизации из-за их исторической краткосрочности. Переходы между формами интеграции культуры - процессы интеграции и дезинтеграции - он также оставил за пределами своего рассмотрения, по-видимому, из-за сложности их генетической реконструкции. Механизм социокультурных трансформаций и способы их практического регулирования оказалось более удобным проанализировать на материале долгосрочных социокультурных трансформаций между различными логически интегрированными формами культуры.

\section{АОАГОСРОЧНЫЕ СОЦИОКУАЬТУРНЫЕ \\ ТРАНСФОРМАЦИИ}

Как известно, в рамках своей концепции социокультурной динамики П. А. Сорокин выделял четыре типа культур: две чистые (чувственная и идеациональная) и две смешанные (псевдоидеациональная и идеалистическая). Исторически первична, на его взгляд, псевдоидеациональная культура и соответствующая ментальность, характеризующаяся чувственным восприятием и смутными фрагментарными идеями. Ее 
формируют суровые внешние обстоятельства, которые требуют придерживаться модели выживания. Она присуща части первобытных племен, массе бедного и угнетенного населения. В более благоприятных условиях псевдоидеациональная ментальность трансформируется в цинично-чувственную форму. Чувственная культура сменяется далее идеациональной культурой, и наоборот. Изредка трансформация может проходить через промежуточную форму идеалистической (интегральной) культуры. Трансформации выделенных типов культур и сопутствующие им социальные изменения П. А. Сорокин и называл социокультурными трансформациями, протекающими в масштабе исторических эпох.

В предельно упрощенном виде базовую в парадигме П. А. Сорокина модель социокультурной трансформации можно свести к циклу «чувственная культура $\leftrightarrow$ идеациональная культура». Целостный процесс отдельной социокультурной трансформации П. А. Сорокин описывал как протекающий по схеме: «кризис $\rightarrow$ катарсис $\rightarrow$ харизма $\rightarrow$ воскресение» (Сорокин, 2006а: 880-885). В фазе кризиса доминантная социокультурная система дезинтегрируется, дробится. Аеградация ведет к социальной поляризации и катарсису - очищению части людей от умирающей культуры и обращению к альтернативной, восходящей культуре. Постепенно появляются лидеры, обладающие харизмой и направляющие строительство нового социокультурного порядка. В фазе воскрешения происходит высвобождение новых творческих сил.

Наиболее основательно П. А. Сорокин описывал переход к чувственной культуре в новоевропейской истории. Поскольку в настоящее время российское общество также переживает переход от идеациональной формы к чувственной форме культуры (Аобреньков, 2010: 9), то особый интерес представляет выделение моделей практического регулирования именно данного типа социокультурной трансформации.

Следует заметить, что социокультурная трансформация представлялась П. А. Сорокину исторически длительным и стихийным процессом, охватывающим многие страны и состоящим из периодически сменяющих друг друга приливов и отливов. Можно ли вообще говорить о каких-либо моделях регулирования трансформаций подобного масштаба?

\section{ПРАКТИЧЕСКОЕ РЕГУАИРОВАНИЕ СОЦИОКУ БТУРНОЙ ТРАНСФОРМАЦИИ: МОАЕАЬ САЕРЖИВАНИЯ}

С учетом этой объективной закономерности в ситуации социокультурной трансформации П. А. Сорокин предлагал реализовывать политику, во-первых, самоограничения в экспансии восходящего социокультурного процесса и, во-вторых, сохранения (резервирования) альтернатив как источника последующих трансформаций. Например, в отношении перемены взглядов на время он писал следующее: «В качестве практической морали можно адресовать сторонникам этернализма, темпорализма и “уравновешенных" теорий следующие слова: если темпоралисты сейчас находятся в седле, у них есть причина радоваться; их вера господствует, а всякое господство вызывает радость. Но пусть их радость, так же как и печаль этерналистов, не будет слишком большой; рано или поздно темпорализм начнет клониться к упадку, а этернализм снова победит. Если сегодня этернализм подавлен, то это значит, что он будет господствовать завтра. Так было, и так, вероятно, сохранится и в будущем. По этой причине различным фракциям не следует непременно воевать друг с другом, лучше прийти к выводу, что их кредо вмещает в себя не всю истину, а кредо их противника 
не во всем плохо и ошибочно» (Сорокин, 2006а: 406). Это поможет, на его взгляд, избежать кратковременных вспышек экстремизма с обеих сторон.

Можно сказать, что данная модель практического регулирования социокультурных трансформаций, действующая в условиях перехода общества к чувственной культуре, основывается на упоминаемом П. А. Сорокиным принципе «живи и давай жить другим» (там же: 596). В политической науке данная модель определяется как модель «сдержанности», «самоограничения», «неагрессивного противостояния» или «мирного сосуществования».

Очевидно, что неизбежным дополнением к «модели сдержанности» является политика «сдерживания», проводимая стороной, чьи позиции в текущей социокультурной трансформации ослабевают (Mandelbaum, 2019). Аанная политика включает прежде всего «мобилизацию оппозиционных сил» (Сорокин, 2014: 289). Мобилизация предусматривает сплочение против общих врагов, прекращение вражды между оппозиционными силами, установление сотрудничества и дружбы, а затем единодушную и настоящую борьбу против общих врагов (Сорокин, 2018: 416).

Рассматривая ситуацию социокультурной трансформации на примере войны, угрожающей в случае поражения сменой социокультурного порядка, П. А. Сорокин подчеркивал, что мобилизация и сплочение необходимо приобретают «тоталитарный крен». Это предполагает централизацию, повышение уровня организованности и регламентации, жесткую дисциплину и постоянный контроль, ограничение прав и свобод, так как это увеличивает шансы на победу (Сорокин, 2006а: 645). Такой «тоталитарный крен», по оценке П. А. Сорокина, воспринимается участниками сопротивления как «подлинное общественное благодеяние», а население принимает с готовностью даже диктатуру (там же: 655). Очевидно, что эта борьба должна следовать модели «сдержанности» и только сдерживать культуру, эпоха которой наступает.

В целом эта базовая модель практического регулирования социокультурной трансформации может быть определена как модель «сдерживания» себя и контрсубъекта. Важно обратить внимание на то, что эта модель регулирования интерсубъектна, направлена и на себя, и на противника. Соответствующую модель волей-неволей вынужден реализовывать и контрсубъект.

Субъекты регулирования социокультурной трансформации, по П. А. Сорокину, чрезвычайно разнообразны. Это семья, клан, государство, различные религиозные организации, профессиональные союзы и национальные группы, корпорации, политические партии, общественные организации и т. А. (там же: 657-658). Все эти организованные социальные субъекты, заключая союзы и меняя лагеря, проводят политику сдерживания по отношению к контрсубъектам. В сети отношений взаимного сдерживания ни одна группа не имеет монопольного положения, ее относительная сила и тоталитаризм флуктуируют: «В какое-то время, например в Средние века, церковь может быть самой могущественной группой, в другое - как сейчас - ее власть и всеохватность снижаются, а государства, наоборот, растут» (там же: 631). При либерализации регулирование децентрализуется и возрастает роль корпоративного (частного) регулирования со стороны церкви, школы, семьи и т. А. Поэтому в каждой конкретной социокультурной ситуации необходимо диагностировать как направленность социокультурной трансформации, так и ее основных субъектов, осуществляющих по отношению друг к другу политику сдерживания. 
АОГОВОРНО-ПРИНУАИТЕАЬНАЯ МОАЕАЬ ПРАКТИЧЕСКОГО РЕГУАИРОВАНИЯ СОЦИОКУАЬТУРНОЙ ТРАНСФОРМАЦИИ

По наблюдениям П. А. Сорокина, при переходе в Новое время к чувственной культуре в странах Европы на общегосударственном уровне реализовывалась модель практического регулирования, которую условно можно обозначить как «договорнопринудительную» (Сорокин, 2006а: 758). Первоначально в этой модели превалировала насильственная составляющая ( «деспотический этатизм»), а по мере воспитания договороспособности большее значение имел контрактуализм.

Тогда требовалось при помощи физического насилия и наказаний укрощать, смирять и муштровать первоначально не знавшего меры чувственного человека, который «был склонен к насилию, чрезмерно эмоционален, жаден» (там же: 595). Этим П. А. Сорокин отчасти объяснял создание в XVII-XVIII вв. регулярных государств

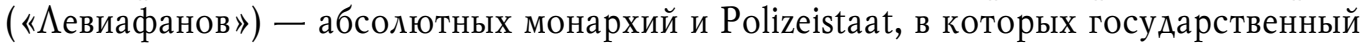
контроль и регламентация приобрели чрезвычайные масштабы (там же: 643-644).

Только после нескольких столетий «муштры», как полагал социолог, чувственный человек на Западе стал уравновешенным, разумным и солидным гражданином «договорного» типа, осознавшим, что «контрактуализм - может быть, самый лучший и удобный метод ведения дел» (там же: 595). Результат свершившейся социокультурной трансформации - это «договорный социокультурный дом», включающий «договорное общество», «договорную демократию», «договорный капитализм» (там же: 882).

Хотя деспотический этатизм и контрактуализм хронологически противопоставлены, П. А. Сорокин не случайно рассматривает их как два варианта реализации договорно-принудительной модели. Хорошо известно, что в XVI-XVII вв. в Западной Европе активно пропагандировались идеи ковенанта (договорных отношений Бога, государя и народа) и контрактуализма (общественного договора) (Lessnoff, 1990: 42-43). На практике они воплощались в создании федеративных государств. Контрактуализм не только сопутствовал деспотическому этатизму, но и обеспечивался им, так как соблюдение договоров возможно только в условиях сильного государства. Таким образом, это дополнительные по отношению друг к другу модели практического регулирования социокультурной трансформации - перехода социального организма от идеалистической к чувственной культуре.

\section{МОАЕАЬ ТВОРЧЕСКОГО И ВСЕОБЩЕГО АИАЕРСТВА}

Экспансия чувственной культуры, которую приходится регулировать, направляется, в свою очередь, не знающими меры чувственными людьми. Они воплощают в себе эту культуру, ее успех и ведут за собой остальных.

Такую модель практического регулирования социокультурной трансформации П. А. Сорокин определяет как «творческое лидерство» (Сорокин, 2006а: 23). В исследованиях организационной культуры и корпоративного менеджмента генезис модели творческого лидерства обычно связывают с публикациями 1960-х гг. (Mainemelis, Kark, Epitropaki, 2015). Анализ наследия социолога показывает, что идея выделения такого типа лидерства высказана им значительно ранее и была отнесена не только к уровню отдельных организаций, но и к мировому сообществу цивилизаций в целом.

Важно подчеркнуть, что в категорию лидеров включается широкий круг лиц. К лидерам чувственной культуры - носителям, создателям и блюстителям наиболее зна- 
чимых чувственных ценностей - П. А. Сорокин отнес состоятельных людей и военных, политиканов и махинаторов, ученых и изобретателей, а также «жуликов и “боссов”, вплоть до всесильных руководителей преступных банд» (Сорокин, 2006а : 599). Аидеры идеациональной культуры - это аскеты, святые, священнослужители и духовные учителя, вокруг которых в конечном счете образуются теократические политико-экономические режимы (там же: 664).

Таким образом, лидерами могут быть практически все люди. По мнению П. А. Сорокина, в условиях социокультурной трансформации в утверждении новых ценностей важное значение имеет «последовательное, честное и решительное участие в этой деятельности всех ответственных людей, где каждый действует наиболее подходящим Аля него образом» (Сорокин, 2006b: 147). Поэтому можно говорить о возможности реализации модели всеобщего лидерства.

Идея того, что лидерами должны быть все, выдвинута относительно недавно применительно к обучающимся организациям (Senge et al., 1999). Но, как показывает проведенный анализ, на самом деле она сформулирована П. А. Сорокиным. Он, в частности, писал: «Если человек одарен искрой творчества, то он может ощутимо облагороАить социокультурный мир, используя свой талант для создания реальных ценностей и отказываясь злоупотреблять им для поддержки псевдоценностей вообще и сексуальной дряни в особенности» (Сорокин, 2006b: 147). С этим суждением можно согласиться с оговоркой в том смысле, что на этот «великий отказ» от поддержки псевдоценностей, позднее пропагандировавшийся Г. Маркузе (The Great Refusal ... , 2016), все-таки способен каждый человек. Поэтому представляется обоснованным говорить о такой модели практического регулирования социокультурной трансформации, как всеобщее лидерство.

\section{ЗАКАЮЧЕНИЕ}

Подводя итоги проведенного анализа идейного наследия П. А. Сорокина по заявленной теме, можно сделать следующие обобщающие выводы.

С позиций его учения по отношению к отдельным социальным организмам представляется возможным выделить несколько типов социокультурных трансформаций, протекающих по циклически организованным схемам:

- формы социокультурной самоорганизации: анархическая - либеральная - авторитарная - тоталитарная;

- формы культурной интеграции: конгломерация (скопление) - ассоциация под воздействием общего внешнего фактора - причинная (функциональная) интеграция - логико-смысловое целое;

- формы логически интегрированных культур: псевдоидеациональная - чувственная - идеациональная - идеалистическая.

Модели практического регулирования П. А. Сорокин описывал по отношению к долгосрочным социокультурным трансформациям логически интегрированных культур. По результатам проведенного им анализа динамики чувственной культуры (на материале европейских обществ Нового времени) можно выделить следующие модели практического регулирования связанных с нею социокультурных трансформаций:

- модель сдерживания;

- договорно-принудительная модель;

- модель творческого и всеобщего лидерства. 
Эти модели реализуются как на уровне государств, так и на уровне локальных сообществ и отдельных личностей. Субъекты регулирования (и саморегуляции), соответственно, разнообразны - как по своему социальному статусу и положению, так и по степени исторического влияния.

В ходе конкретной социокультурной трансформации, очевидно, первоначально реализуется модель лидерства. Затем участвующими субъектами применяется модель сдерживания. Аалее становление новой формы культуры обеспечивает иная модель, примером которой является договорно-принудительная модель, регулирующая динамику чувственной культуры методами деспотического этатизма и контрактуализма.

\section{СПИСОК АИТЕРАТУРЫ}

Абрамова, М. А., Костюк, В. Г. (2017) Социокультурная трансформация: концептуальные подходы, динамика, актуализация исследования сообществ // Сибирский философский журнал. Т. 15. № 2. С. 92-100.

Аобреньков, В. И. (2010) Кризис нашего времени в контексте теории социокультурной динамики П. А. Сорокина: пророчество о судьбах мира и России // Вестник Московского университета. Серия 18. Социология и политология. № 1. С. 5-21.

Сорокин, П. А. (2006а) Социальная и культурная динамика. М. : Астрель. 1176 с.

Сорокин, П. А. (2006b) Американская сексуальная революция. М. : Проспект. 152 с.

Сорокин, П. А. (2014) Главные тенденции нашего времени // Партнерство цивилизаций. № $1 / 2$. С. 281-297.

Сорокин, П. А. (2015) Аистки из русского дневника. Социология революции. Сыктывкар : Анбур. 848 с.

Сорокин, П. А. (2018) Кризис нашего времени. Россия и Соединенные Штаты. Сыктывкар : Анбур. 640 с.

Lessnoff, M. H. (1990) Social contract theory. New York : New York University Press. 244 p.

Mainemelis, C., Kark, R., Epitropaki, O. (2015) Creative Leadership: A Multi-Context Conceptualization // The Academy of Management Annals. № 9 (1). P. 393-482.

Mandelbaum, M. (2019) The New Containment. Handling Russia, China, and Iran // Foreign Affairs. 21 Febr. Vol. 98. № 2. P. 123-131.

Mangone, E. (2018) Social and Cultural Dynamics. Revisiting the Work of Pitirim A. Sorokin. Cham, Springer International Publishing AG. 89 p.

Senge, P., Kleiner, A., Roberts, C., Ross, R. et al. (1999) The Dance of Change: The Challenges of Sustaining Momentum in Learning Organizations. London : Nicholas Brealey Publishing. 608 p.

The Great Refusal: Herbert Marcuse and Contemporary Social Movements (2016) / ed. by P. Funke, A. Lamas, T. Wolfson. Philadelphia : Temple University Press. 424 p.

Аата поступления: 06.05.2019 г.

\section{SOCIOCULTURAL TRANSFORMATIONS: PRACTICAL REGULATORY MODELS \\ YU. V. POPKOV \\ InStitute of Philosophy and LaW, Siberian BRANCH of the RAS \\ E. A. TYUGASHEV \\ NOVOSIBIRSK NATIONAL RESEARCH StATE UNIVERSITY}

The paper updates the issue of the dependency between the description of the forms and contents of sociocultural transformations and the interpretation of the sociocultural concept per se. The authors argue the variability of the practical expertise in the regulation of sociocultural transformations. They draw upon the explication of conceptually significant ideas of P. A. Sorokin, the founder of the theory of sociocultural dynamics, to analyse certain practical regulatory models of sociocultural transformations. 
Qualitative reforms of various culture types and their concurrent social changes were called sociocultural transformations, happening on a scale of historical eras by the famous sociologist. According to P. A. Sorokin's theory, different grounds make it possible to define several types of sociocultural transformations: by forms of sociocultural self-organisation, by forms of cultural integration, and by forms of logically integrated cultures. P. A. Sorokin described practical regulatory models in reference to long-term sociocultural transformations of logically integrated cultures.

Utilising the results of his research into the dynamics of sensual culture (based on the material of the modern age European societies) the following practical regulatory models of the associated sociocultural transformations can de defined: deterrence model, agreement-forced model, and the model of creative and universal leadership. Considering that contemporary Russian society is also undergoing the transition from the ideational to the sensual culture form, P. A. Sorokin's ideological legacy may prove useful for the conceptual characteristic of practical regulatory models of urgent sociocultural transformations.

Keywords: sociocultural dynamics; sociocultural transformations; P. A. Sorokin

\section{REFERENCES}

Abramova, M. A. and Kostiuk, V. G. (2017) Sotsiokul'turnaia transformatsiia: kontseptual'nye podkhody, dinamika, aktualizatsiia issledovaniia soobshchestv. Sibirskii filosofskii zhurnal, vol. 15, no. 2, pp. 92-100. (In Russ.).

Dobren'kov, V. I. (2010) Krizis nashego vremeni v kontekste teorii sotsiokul'turnoi dinamiki P. A. Sorokina: prorochestvo o sud'bakh mira i Rossii. Vestnik Moskovskogo universiteta. Seriia 18. Sotsiologiia i politologiia, no. 1, pp. 5-21. (In Russ.).

Sorokin, P. A. (2006a) Sotsial'naia i kul'turnaia dinamika. Moscow, Astrel'. 1176 p. (In Russ.).

Sorokin, P. A. (2006b) Amerikanskaia seksual'naia revoliutsiia. Moscow, Prospekt. 152 p. (In Russ.).

Sorokin, P. A. (2014) Glavnye tendentsii nashego vremeni. Partnerstvo tsivilizatsii, no. 1/2, pp. 281-297. (In Russ.).

Sorokin, P. A. (2015) Listki iz russkogo dnevnika. Sotsiologiia revoliutsii. Syktyvkar, Anbur. 848 p. (In Russ.).

Sorokin, P. A. (2018) Krizis nashego vremeni. Rossiia i Soedinennye Shtaty. Syktyvkar, Anbur. 640 p. (In Russ.).

Lessnoff, M. H. (1990) Social contract theory. New York, New York University Press. 244 p.

Mainemelis, C., Kark, R., Epitropaki, O. (2015) Creative Leadership: A Multi-Context Conceptualization. The Academy of Management Annals, no. 9 (1), pp. 393-482.

Mandelbaum, M. (2019) The New Containment. Handling Russia, China, and Iran. Foreign Affairs, 21 Febr., vol. 98, no. 2, pp. 123-131.

Mangone, E. (2018) Social and Cultural Dynamics. Revisiting the Work of Pitirim A. Sorokin. Cham, Springer International Publishing AG. 89 p.

Senge, P., Kleiner, A., Roberts, C., Ross, R. et al. (1999) The Dance of Change: The Challenges of Sustaining Momentum in Learning Organizations. London, Nicholas Brealey Publishing. 608 p.

The Great Refusal: Herbert Marcuse and Contemporary Social Movements (2016) / ed. by P. Funke, A. Lamas and T. Wolfson. Philadelphia, Temple University Press. 424 p.

Submission date: 06.05.2019.

Попков Юрий Владимирович - доктор философских наук, профессор, главный научный сотрудник Института философии и права Сибирского отделения Российской академии наук. Адрес: 630090, Россия, г. Новосибирск, ул. Николаева, д. 8. Тел.: +7 (383) 330-22-40. Эл. адрес: yuripopkov54@mail.ru

Тюгашев Евгений Александрович - доктор философских наук, доцент кафедры теории и истории государства и права, конституционного права Института философии и права Ново- 
сибирского национального исследовательского государственного университета. Адрес: 630090, Россия, г. Новосибирск, ул. Пирогова, д. 2. Тел.: +7 (383) 269-67-41. Эл. адрес: filosof10@yandex.ru

Popkov Yuriy Vladimirovich, Doctor of Philosophy, Professor, Chief Research Fellow, Institute of Philosophy and Law, Siberian Branch, Russian Academy of Sciences. Postal address: 8, Nikolayeva St., Novosibirsk, Russian Federation, 630090. Tel.: +7 (383) 330-22-40. E-mail: yuripopkov54@mail.ru

Tyugashev Evgeniy Aleksandrovich, Doctor of Philosophy, Associate Professor, Department of Theory and History of State and Law, Constitutional Law, Institute for Philosophy and Law, Novosibirsk National Research State University. Postal address: 2, Pirogova St., Novosibirsk, Russian Federation, 630090. Tel.: +7 (383) 269-67-41. E-mail: filosof10@yandex.ru 